\title{
Glass Fractures Made from Different Pellet Shapes- A Preliminary Study
}

\author{
Sughosh Abhyankar*, Ankit Srivastava, Vijay Kumar Yadav, Kriti Nigam and Abhimanyu Harshey \\ A.P.J.A.K. Inst. of Forensic Science \& Criminology, Bundelkhand University, India
}

Submission: May 01, 2018; Published: May 08, 2018

*Corresponding author: Sughosh Abhyankar, PG Student, Dr. A.P.J.A.K. Inst. of Forensic science \& Criminology, Bundelkhand University, Jhansi- 284128, India, Tel: 919532911914; Email: sughoshabhyankar@gmail.com

\begin{abstract}
Glass is the most common type of evidence found at crime scenes. Generally, it is encountered in scenes involving housebreaking, road accidents, shooting incidents etc. At the scene of occurrence glass is commonly found in shattered condition but sometimes an intact piece of glass may be found on the window frame or at any other place with some patterns or marks on its surface. These patterns are termed as fractures and are formed when any projectile hits the glass surface. The study of such fractures is of great importance and is useful in linking of events with evidences in shooting cases. The present study also focuses on the analysis of such type of fracture pattern made on window panes of variable thickness made by .177"/ 4.5mm lead pellets of different shapes (round nose \& flat nose). Window panes were fractured by $.177 " / 4.5 \mathrm{~mm}$ caliber Air Gun manufactured in India. The panes were kept fixed in a metal frame and firing was done from a fixed distance. Samples were analyzed under fixed parameters and observations were noted. The result had been arranged in a tabular manner with its graphical representation. The findings of this work show significant trends. This work glorifies the need of extended study of the current approach.
\end{abstract}

Keywords: Crime scene; Fracture pattern; Air Gun; Glass; caliber; Pellet shape

\section{Introduction}

The glass is hard, brittle and amorphous in nature. Due to its characteristics, physical properties glass found its important part as physical evidence. Glass in one form or other is found at various crime scenes. An investigating officer or forensic expert may encounter glass at shooting incidences where the target has been on window panes, windshields of automobiles etc. Therefore, analysis of fracture patterns on a glass surface is of great importance to the forensic community as it helps in characterizing and answering many related questions. Formation and types of fracture patterns on glass surface has been described by various authors in their books; [1-4]. Analysis of fracture patterns reveals information about the direction of force, the cause of fracture etc. Glasses are super cooled liquids and they possess a number of properties: transparency with or without color, durability, electrical and thermal resistance, a range of thermal expansions, with hardness, rigidity, and stability [5]. On the basis of various physical properties (basically refractive index and density), glass evidence can be differentiated and can be identified or individualized [6].

Griffith explained the basic mechanics of glass fracture and stated that fracture always initiated from pre-existing flaws know as Griffith Flaws [7]. When a projectile hits a glass surface glass bends and when its elasticity is reached the glass breaks in the forms of fracture $[2,4]$. The two types of fracture patterns are formed when a projectile hits glass surface - Radial and Concentric. Another type of fracture formed by penetration of high velocity of projectiles is cone fracture. This fracture is characteristics with wider on the exit side and smaller on the entry side of the bullet hole. An Air Gun is an arm that propels projectiles by means of mechanically pressurized air or other gases which involves no chemical reactions, in contrast to explosive propellant which involves an exothermic chemical reaction [8]. Both the rifle and handgun forms (Air Rifle and Air Pistol) typically propel metallic projectiles, either the nonspherical pellets or the spherical BBs. Certain types of Air Guns (usually rifles) may also propel arrows or darts. The first air gun documented to be developed was in the 1500s. The guns are been used for hunting, sporting and warfare purposes.

\section{Materials and Methodology}

The study has been carried out to study the effect of pellets shapes on glass fracture patterns made by .177" (4.5mm) caliber air rifle. For this research work window panes of variable thickness were taken namely $3 \mathrm{~mm}, 4 \mathrm{~mm}, 5 \mathrm{~mm}$ and $6 \mathrm{~mm}$. Two different shapes of pellets shapes were taken - Round Nose \& Flattened Nose. Window panes were fitted in a metal frame of dimension $1 \mathrm{ft} \times 1 \mathrm{ft}$ with the help of clay. The frame was kept at fixed distance of $12 \mathrm{ft}$ from muzzle end of the weapon. Test firing 


\section{Journal of Forensic Sciences \& Criminal Investigation}

was conducted by .177" air gun keeping the frame perpendicular with muzzle of the weapon. The specifications of the Air rifle and pellets used during experiment are described in Table 1.

Table 1: Specification of the Weapon and Pellet Used.
After test firing, samples were numbered and photographed. Measurements were taken with Vernier Caliper. Following measurements were taken into account.

\begin{tabular}{|c|c|}
\hline \multicolumn{2}{|c|}{ Specifications of Air Rifle } \\
\hline Name of the Manufacturer & Precihole Sports Pvt. Ltd, Thane, Maharashtra, India \\
\hline Power source & Spring piston \\
\hline Mechanism & Break barrel \\
\hline Caliber & $0.177^{\prime \prime}(4.5 \mathrm{~mm})$ \\
\hline Barrel length & $450 \mathrm{~mm}$ \\
\hline Action & Single shot \\
\hline \multicolumn{2}{|c|}{ Specifications of the Pellets } \\
\hline Material & Lead \\
\hline Brand & Magnum \\
\hline Caliber & $0.177 "$ (4.5mm) \\
\hline Shape & Round Head Flat Head \\
\hline Source: SX100 Owner Manual Published by Precihole Sports, Pvt. Ltd, Thane, Maharashtra, India \\
\hline \multicolumn{2}{|c|}{} \\
\hline
\end{tabular}

a. Radial fracture count

b. Concentric Fracture count

c. Diameter of Pellet Hole (Marked as A in Figure 1)

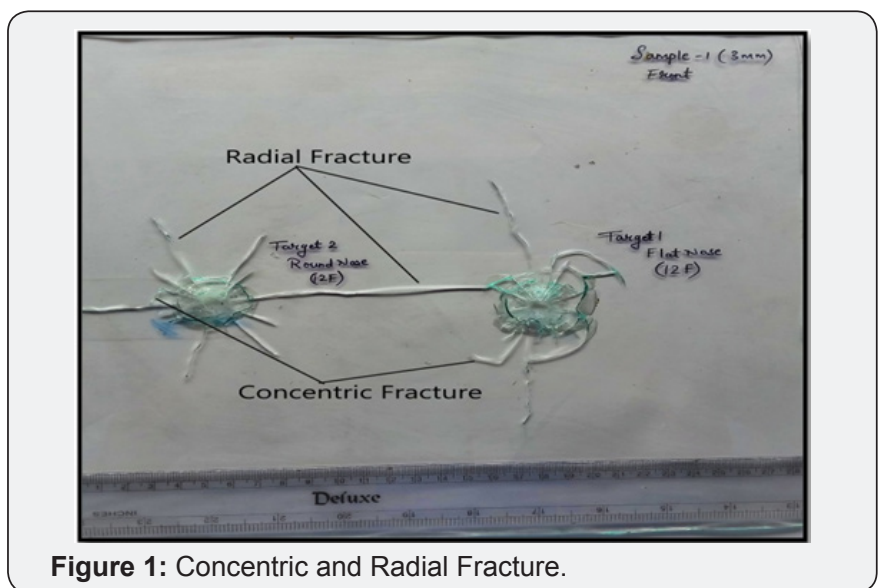

d. Thickness of Mist Zone (Marked as C in Figure 2)

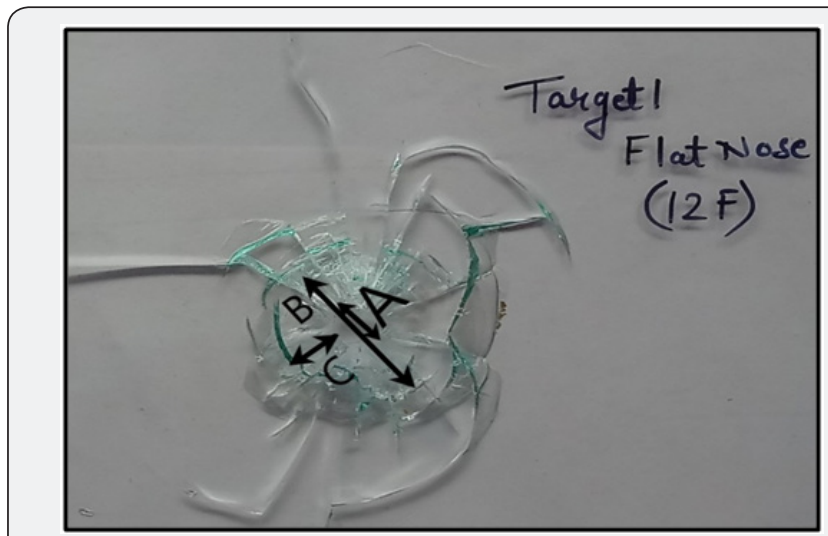

Figure 2: Different Characters Shown. e. Diameter of Mist Zone (Marked as B in Figure 3)

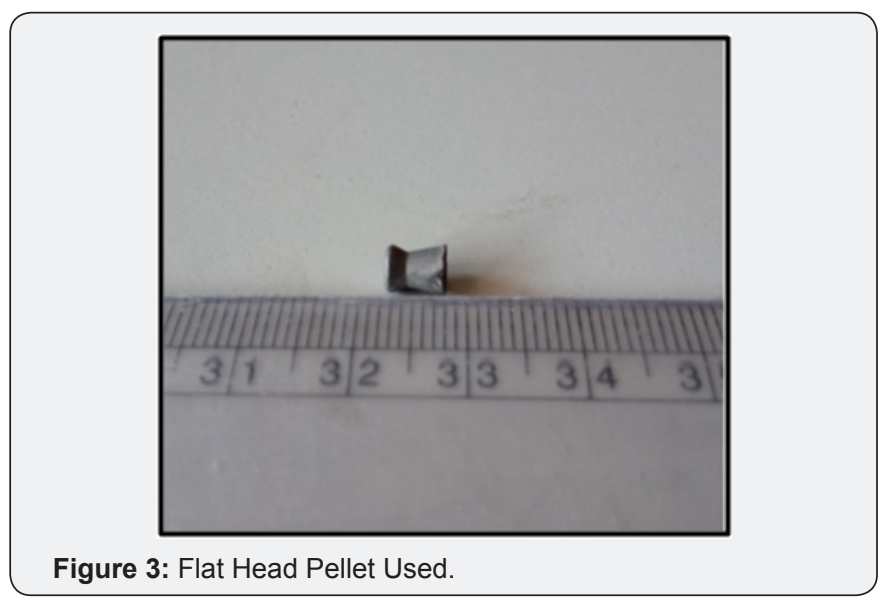

\section{Result}

Window panes of thickness $3 \mathrm{~mm}, 4 \mathrm{~mm}, 5 \mathrm{~mm} \& 6 \mathrm{~mm}$ were test fired using above mentioned weapon. After test firing, the fracture pattern developed on the glass sheet was analyzed. The data was plotted on a graph to show the regularity in the characteristics and the trend they follow. Tables $2 \& 3$ summarizes the measurement obtained after analysis. All the glass panes of different thickness show regularity in fracture pattern when viewed. Figures 4-10 represents graphs for round head and flat head shaped pellets, which are plotted together to show comparative study of different characteristics taken into account. Also the trends in whole diameter were plotted separately and are represented through line graph in Figures 1114. On the basis of above observation it can be opined that there is a consistency in hole diameter for a particular pellet shape i.e. for round head pellet all the measurements show linearity irrespective of glass thickness and same trend follow for flat head pellet. 


\section{Journal of Forensic Sciences \& Criminal Investigation}

Table 2: Measurements from Round Head Pellet.

\begin{tabular}{|c|c|c|c|c|c|}
\hline Sample No. & Hole diameter & Radial Count & Concentric Count & Thickness of Mist Zone & Diameter of Mist Zone \\
\hline \multicolumn{6}{|c|}{$3 \mathrm{~mm}$} \\
\hline 1 & $5.16 \mathrm{~mm}$ & 15 & 6 & $11.75 \mathrm{~mm}$ & $33.82 \mathrm{~mm}$ \\
\hline 2 & $6.35 \mathrm{~mm}$ & 11 & 9 & $11.21 \mathrm{~mm}$ & $28.76 \mathrm{~mm}$ \\
\hline 3 & $5.96 \mathrm{~mm}$ & 8 & 8 & $10 \mathrm{~mm}$ & $25.96 \mathrm{~mm}$ \\
\hline \multicolumn{6}{|c|}{$4 \mathrm{~mm}$} \\
\hline 1 & $4.93 \mathrm{~mm}$ & 11 & 6 & $9.3 \mathrm{~mm}$ & $28.46 \mathrm{~mm}$ \\
\hline 2 & $5.56 \mathrm{~mm}$ & 10 & 6 & $14.27 \mathrm{~mm}$ & $41.95 \mathrm{~mm}$ \\
\hline 3 & $6.4 \mathrm{~mm}$ & 8 & 0 & $13.7 \mathrm{~mm}$ & $33.8 \mathrm{~mm}$ \\
\hline \multicolumn{6}{|c|}{$5 \mathrm{~mm}$} \\
\hline 1 & $5.37 \mathrm{~mm}$ & 11 & 6 & $12.37 \mathrm{~mm}$ & $30.10 \mathrm{~mm}$ \\
\hline 2 & $4.76 \mathrm{~mm}$ & 6 & 7 & $19.75 \mathrm{~mm}$ & $49.02 \mathrm{~mm}$ \\
\hline 3 & $6.07 \mathrm{~mm}$ & 10 & 7 & $12.9 \mathrm{~mm}$ & $31.87 \mathrm{~mm}$ \\
\hline \multicolumn{6}{|c|}{$6 \mathrm{~mm}$} \\
\hline 1 & $2.83 \mathrm{~mm}$ & 5 & 3 & $16.1 \mathrm{~mm}$ & $32.2 \mathrm{~mm}$ \\
\hline 2 & $2.66 \mathrm{~mm}$ & 9 & 1 & $13.32 \mathrm{~mm}$ & $31.9 \mathrm{~mm}$ \\
\hline 3 & $2.3 \mathrm{~mm}$ & 10 & 1 & $12.6 \mathrm{~mm}$ & $29.8 \mathrm{~mm}$ \\
\hline
\end{tabular}

Table 3: Measurement from Flat Head Pellet.

\begin{tabular}{|c|c|c|c|c|c|}
\hline Sample No. & Hole diameter & Radial Count & Concentric Count & Thickness of Mist Zone & Diameter of Mist Zone \\
\hline \multicolumn{6}{|c|}{$3 \mathrm{~mm}$} \\
\hline 1 & $5.33 \mathrm{~mm}$ & 20 & 14 & $13.92 \mathrm{~mm}$ & $38.51 \mathrm{~mm}$ \\
\hline 2 & $4.96 \mathrm{~mm}$ & 14 & 8 & $12.57 \mathrm{~mm}$ & $35.07 \mathrm{~mm}$ \\
\hline 3 & $4.6 \mathrm{~mm}$ & 13 & 9 & $11.75 \mathrm{~mm}$ & $32.7 \mathrm{~mm}$ \\
\hline \multicolumn{6}{|c|}{$4 \mathrm{~mm}$} \\
\hline 1 & $4.9 \mathrm{~mm}$ & 15 & 7 & $11.2 \mathrm{~mm}$ & $32.2 \mathrm{~mm}$ \\
\hline 2 & $6.7 \mathrm{~mm}$ & 18 & 8 & $13.85 \mathrm{~mm}$ & $38.82 \mathrm{~mm}$ \\
\hline 3 & $5.6 \mathrm{~mm}$ & 11 & 12 & $17 \mathrm{~mm}$ & $45.33 \mathrm{~mm}$ \\
\hline \multicolumn{6}{|c|}{$5 \mathrm{~mm}$} \\
\hline 1 & $3.73 \mathrm{~mm}$ & 10 & 5 & $15.25 \mathrm{~mm}$ & $37.96 \mathrm{~mm}$ \\
\hline 2 & $5.33 \mathrm{~mm}$ & 7 & 6 & $16.9 \mathrm{~mm}$ & $44.46 \mathrm{~mm}$ \\
\hline 3 & $4.8 \mathrm{~mm}$ & 12 & 7 & $12.27 \mathrm{~mm}$ & $34.15 \mathrm{~mm}$ \\
\hline \multicolumn{6}{|c|}{$6 \mathrm{~mm}$} \\
\hline 1 & $4.9 \mathrm{~mm}$ & 9 & 2 & $15.55 \mathrm{~mm}$ & $40.9 \mathrm{~mm}$ \\
\hline 2 & $5.16 \mathrm{~mm}$ & 7 & 1 & $15.62 \mathrm{~mm}$ & $41.57 \mathrm{~mm}$ \\
\hline 3 & $2.55 \mathrm{~mm}$ & 10 & 3 & $13.65 \mathrm{~mm}$ & $32.4 \mathrm{~mm}$ \\
\hline
\end{tabular}



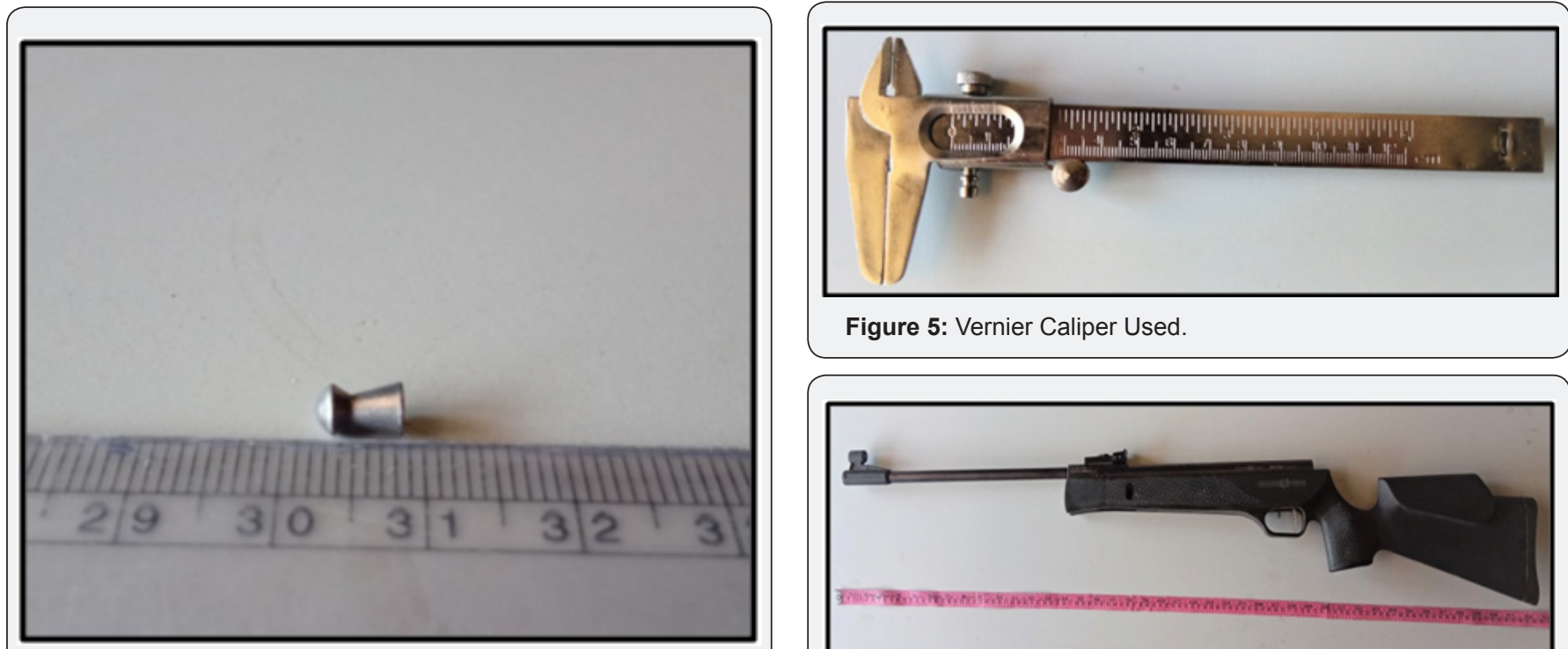

Figure 5: Vernier Caliper Used.

Figure 4: Round Head Pellet Used.

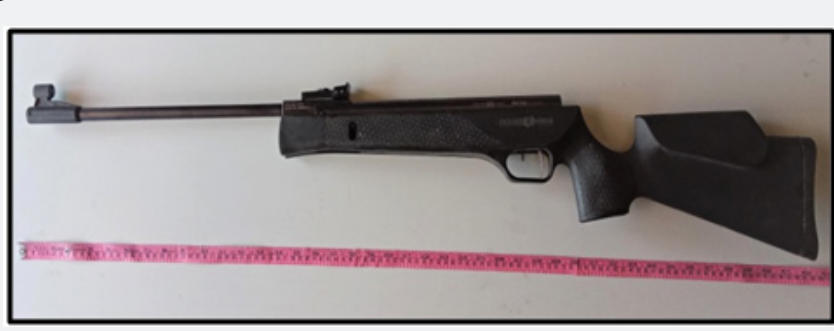

Figure 6: Air Gun Used.

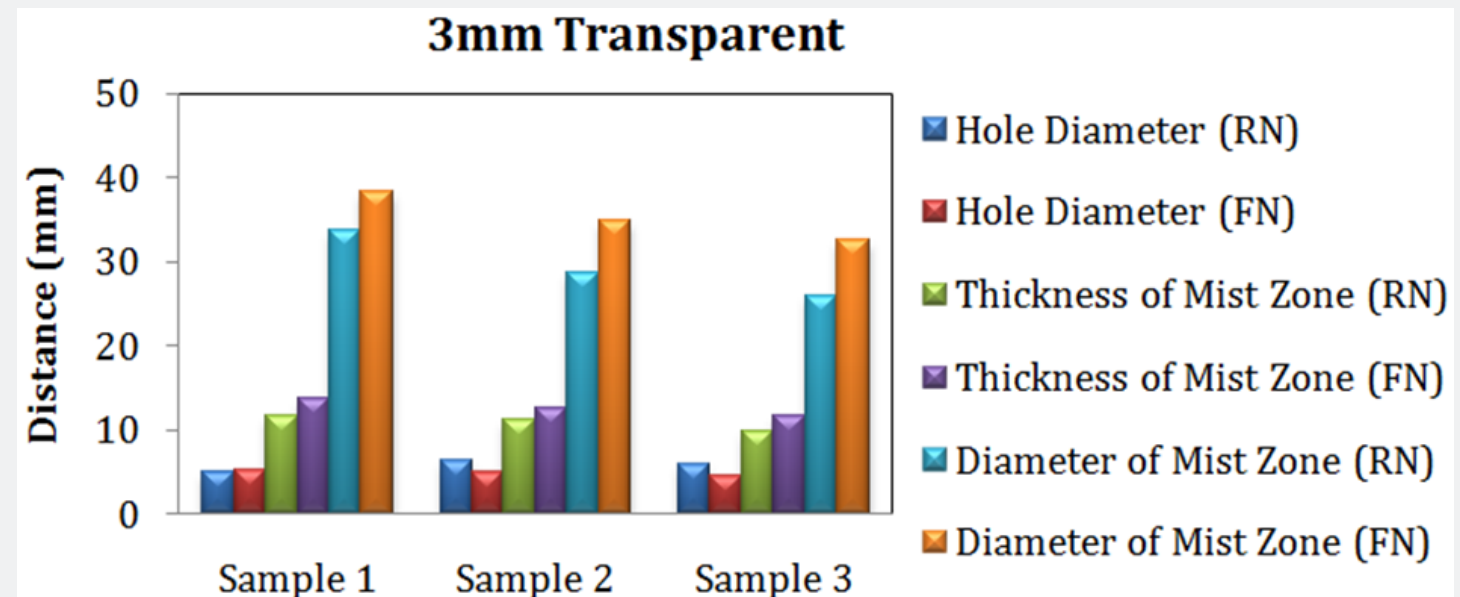

Figure 7: Graphical representation of 3mm Glass Measurements.

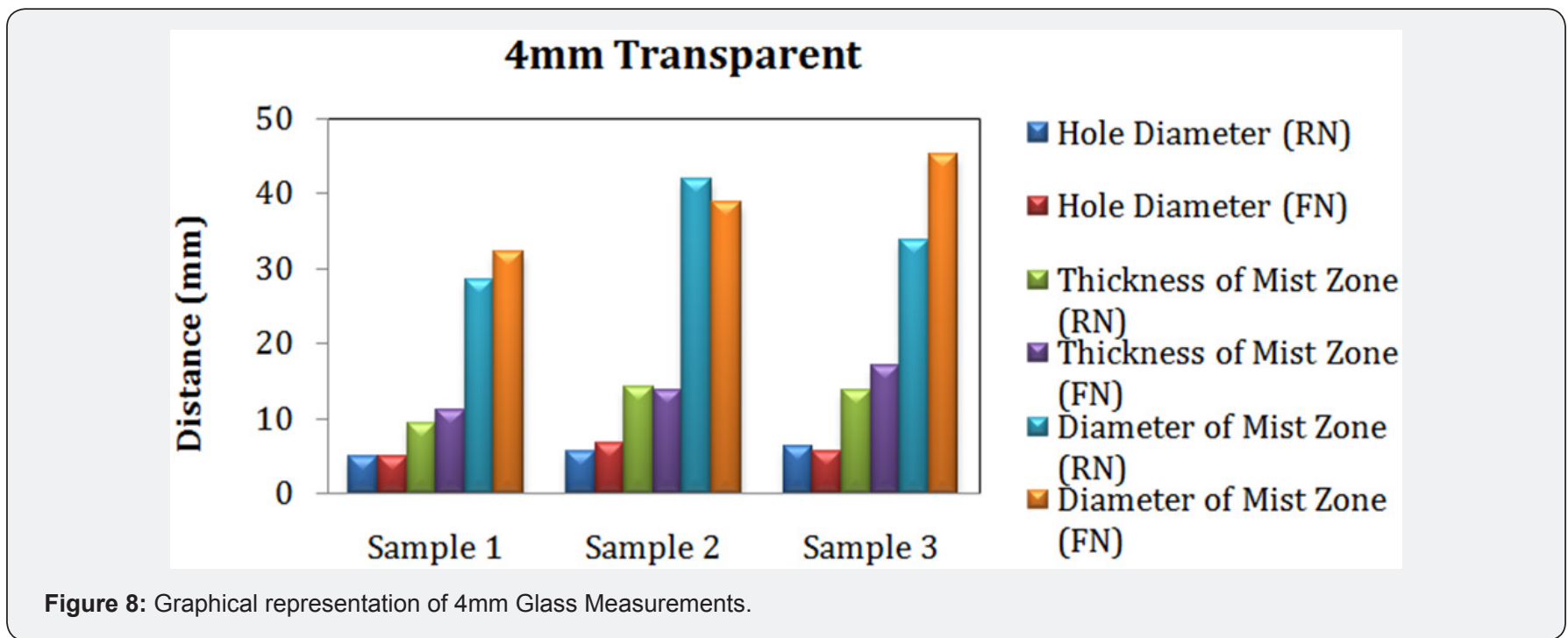




\section{$5 \mathrm{~mm}$ Transparent}

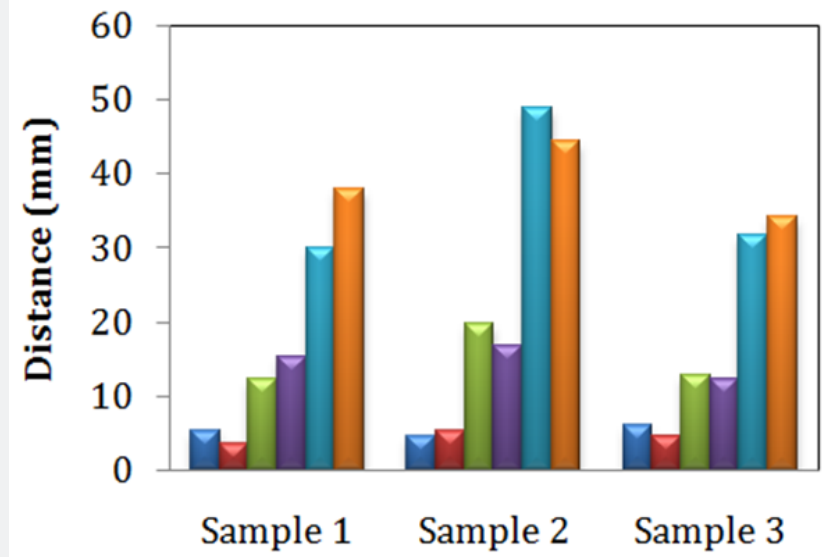

口 Hole Diameter (RN)

口 Hole Diameter (FN)

$\square$ Thickness of Mist Zone (RN)

$\square$ Thickness of Mist Zone (FN)

$\square$ Diameter of Mist Zone (RN)

$\square$ Diameter of Mist Zone (FN)

Figure 9: Graphical representation of $5 \mathrm{~mm}$ Glass Measurements.

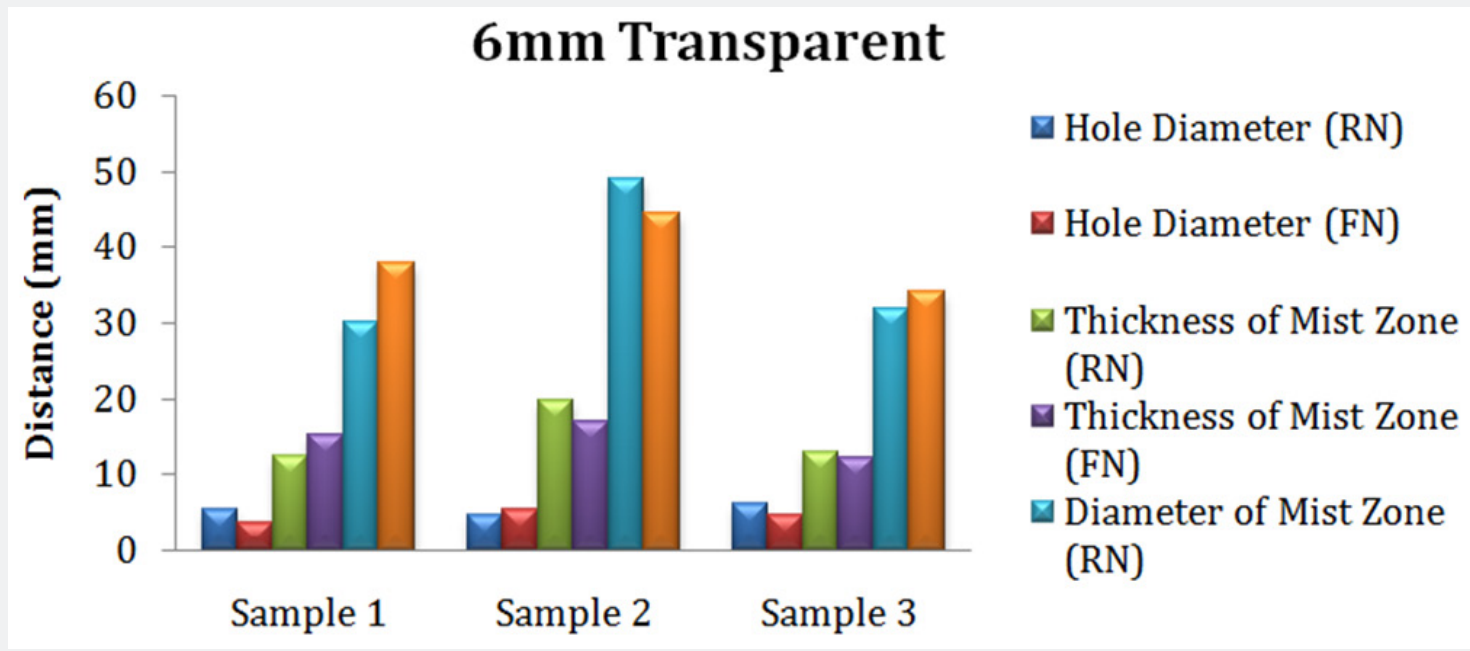

Figure 10: Graphical representation of $6 \mathrm{~mm}$ Glass Measurement.

\section{Trends of Hole Diameter of $4 \mathrm{~mm}$ Glass}

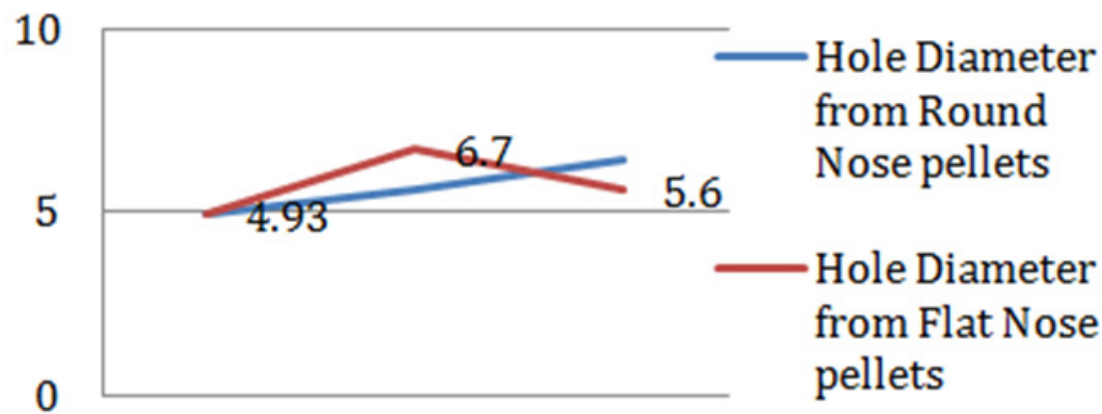

Sample 1 Sample 2 Sample 3

Figure 11: Linear Representation of 3mm Glass. 


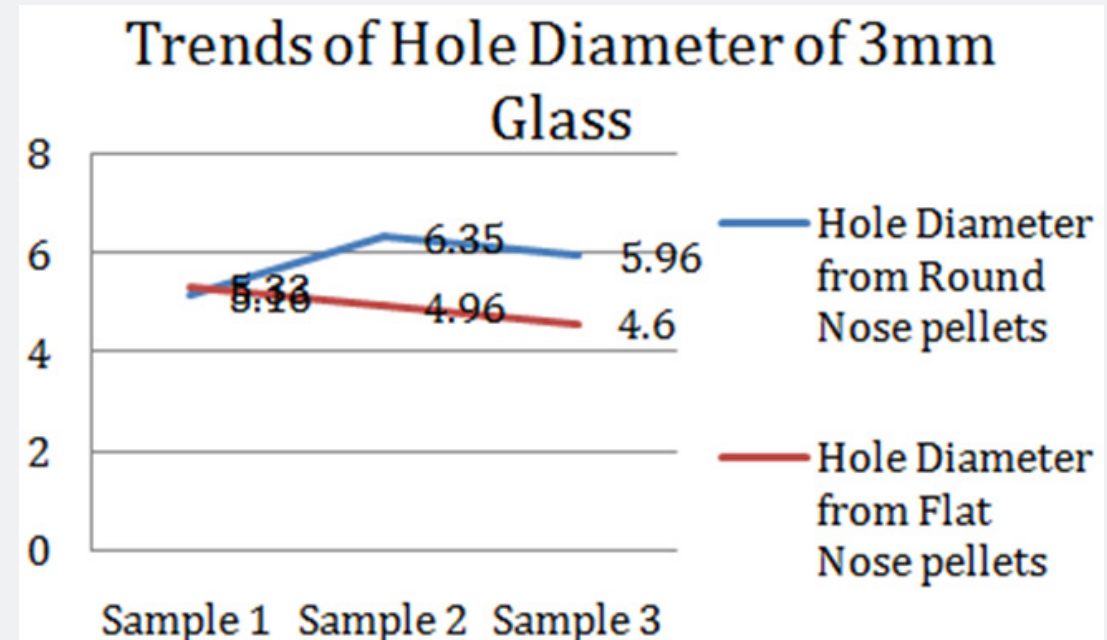

Figure 12: Linear Representations of $4 \mathrm{~mm}$ Glass.

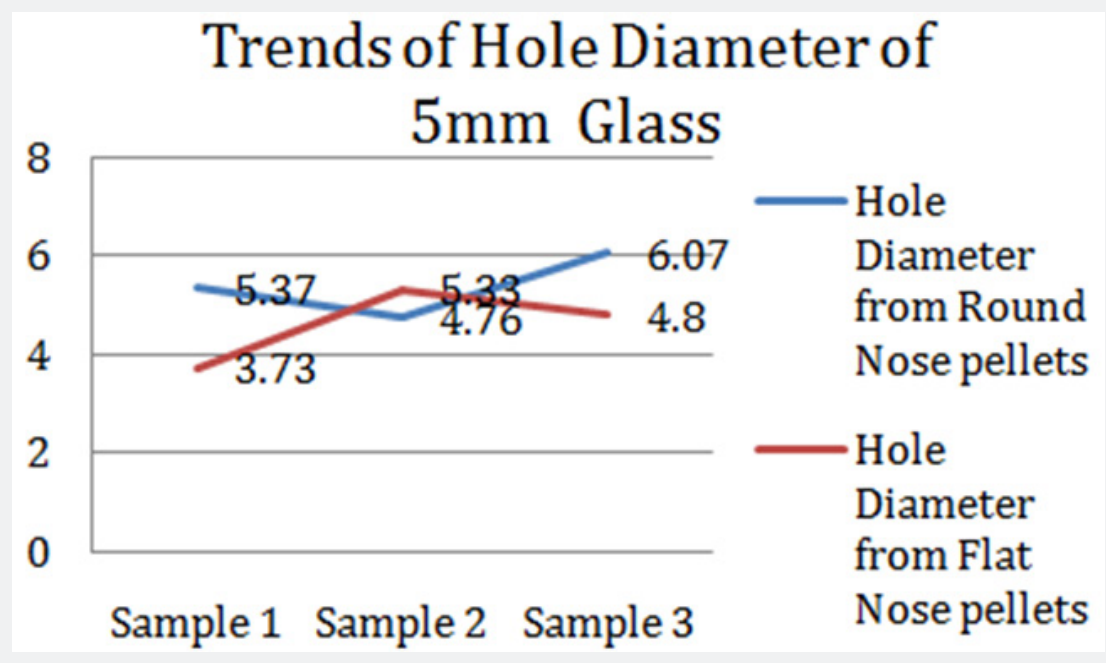

Figure 13: Linear Representations of $5 \mathrm{~mm}$ Glass.

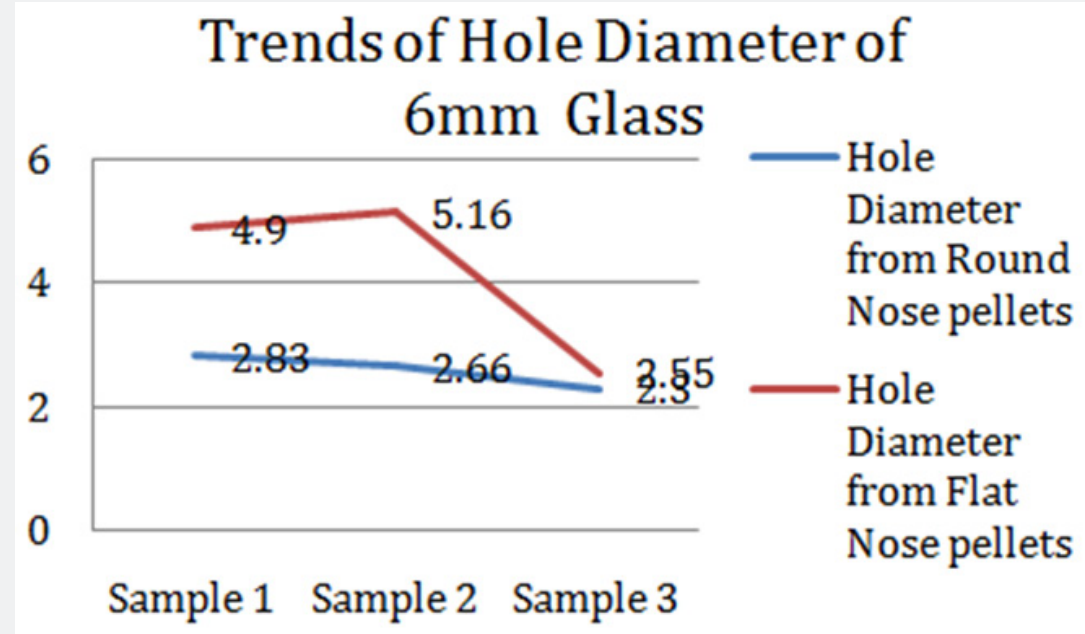

Figure 14: Linear Representation of $6 \mathrm{~mm}$ Glass. 


\section{Discussion}

Various measurements were taken after test firing on glass sheets of different thickness. After firing glass facture pattern were analyzed on the basis of various characters which are discussed previously. On the basis of such observation it was found that the whole diameter formed from round head pellet was completely different from that of flat head pellet. Whole diameter formed range from $2.3 \mathrm{~mm}$ to $6.5 \mathrm{~mm} \& 2.55 \mathrm{~mm}$ to $6.55 \mathrm{~mm}$ for round head and flat head pellets respectively. Harshey. also studied the glass fracture patterns formed from $.177^{\prime \prime}(4.5 \mathrm{~mm})$ on glass sheets of various thickness namely $3 \mathrm{~mm}$, $4 \mathrm{~mm}$ (transparent \& privacy) and $5 \mathrm{~mm}$. They concluded that the whole diameter formed range between $4.77 \mathrm{~mm}$ to $7.5 \mathrm{~mm}$. Their approach was concluded as the hole diameters and other parameters are showing significant rends. Similarly in this study it was found that findings through particular pellet shape are in consistent range. Consistency is well discussed in result section through the liner graphs.

\section{Conclusion}

Different shapes of the pellet are supposed to be producing different ballistic effect. In this study it was found that different pellet shapes gives consistent whole diameter. But the shape of pellet cannot be established on the basis of shape and whole diameter as found in this preliminary study. Both the pellet shape produce hole diameter in a consistent range. The findings of this work may found to be efficacious for the forensic fraternity. The findings may help in criminal investigation as well as for the researchers to create new maxims.

\section{References}

1. O'Hara CE, Osterburg JW (1949) an introduction to Criminalistics. U Miami L Rev.

2. Nabar BS (2008) Forensic science in crime investigation. in ( $3^{\text {rd }}$ edn) Asia Law House, India.

3. Shelby J (2005) Introduction to Glass Science and Technology, $2^{\text {nd }}$ edn The Royal Society of Chemistry, Cambridge, UK.

4. Saferstein R (2006) Criminalities an Introduction to Forensic Science. In ( $9^{\text {th }}$ edn). Prentice Hall, Englewood Cliffs, New Jersey, USA.

5. Copley GJ (2001) the composition and manufacture of glass and its domestic and industrial applications. In Caddy B (edn.) Forensic Examination of Glass and Paint, Taylor \& Francis, New York.

6. Gogotsi GA, Mudrik SP (2010) Glasses: New approach to fracture behavior analysis. Journal of Non-Crystalline Solids 356(20-22): 10211026.

7. Griffith AA (1920) The Phenomena of Rupture and Flow in Solids Philosophical Transactions. Royal Society of London Series A 221(582593).

8. Harshey A, Srivastava A, Yadav V, Nigam K, Kumar A, et al. (2017) Analysis of glass fracture pattern made by .177 " (4.5mm) Caliber air rifle. Egyptian Journal of Forensic Sciences 7(20).

This work is licensed under Creative

DOI: $10.19080 /$ JFSCI.2018.08.555739
Your next submission with Juniper Publishers will reach you the below assets

- Quality Editorial service

- Swift Peer Review

- Reprints availability

- E-prints Service

- Manuscript Podcast for convenient understanding

- Global attainment for your research

- Manuscript accessibility in different formats ( Pdf, E-pub, Full Text, Audio)

- Unceasing customer service

Track the below URL for one-step submission https://juniperpublishers.com/online-submission.php 